\title{
Socioeconomic disparities in prevalence, awareness, treatment, and control of hypertension over the life course in China
}

\author{
Fan Yang, Dongfu Qian", Xueyi Liu, for the Healthy Aging and Development Study Group in Nanjing Medical \\ University and for the Data Mining Group of Biomedical Big Data in Nanjing Medical University
}

\begin{abstract}
Background: The socioeconomically disadvantaged populations are more likely to suffer from hypertension, and few have effectively treated and controlled their hypertension. Research on socioeconomic disparities in prevalence, awareness, treatment, and control of hypertension is warranted to inform the development of new strategies for reducing such health inequities.

Methods: The China Health and Nutrition Survey (CHNS) followed up 20,174 individuals over a 20-year period. We added seven key socioeconomic indicators with age and age-squared into the mixed-effects models to explicitly assess the effect of socioeconomic determinants on hypertension throughout the adult life course.

Results: Prevalence of hypertension was at a higher level in the younger birth cohorts than that in the older generations. Age-related increases in prevalence, awareness, treatment, and control of hypertension were observed over the adult life course. Males, insured and ethnic Han were more likely to suffer from hypertension than their counterparts [coefficient $(95 \%$ confidence intervals): $0.07(0.04,0.09), 0.02(0.01,0.03)$ and $0.05(0.03,0.07)$, respectively]. Hypertension was more prevalent among individuals with higher income who lived in urbanized communities, and less among those with higher education attainment [coefficient ( $95 \%$ confidence intervals): $-0.07(-0.12,-0.016)$ ] across adulthood. High-level urbanization and education increased the probabilities of awareness, treatment, and control of hypertension, while household income decreased them [coefficient (95\% confidence intervals): 0.28(0.17, $0.39), 0.27(0.17,0.37)$ and $0.14(0.08,0.21)$, respectively] over the adult life course.
\end{abstract}

Conclusions: Community urbanicity brought the raise in awareness, treatment, and control of hypertension, but also led to an increase in prevalence of hypertension. People with fewer educational years or higher income may be the disadvantaged population of hypertension over the adult life course in China.

Keywords: Hypertension, China, Life Course, Socioeconomic disparities;

\section{Background}

The prevalence of hypertension in the Chinese adult population increased substantially from around 20 to $34 \%$ between 2002 and 2010 [1], and the rates of awareness, treatment, and control of hypertension are still unacceptably low. More seriously, hypertension contributes to health inequalities in China. The socioeconomically disadvantaged populations are more likely to suffer from

\footnotetext{
* Correspondence: dongfu016@126.com

School of Health Policy \& Management, Nanjing Medical University,

Hanzhong Road 140, Nanjing 210029, Jiangsu Province, People's Republic of China
}

(c) The Author(s). 2017 Open Access This article is distributed under the terms of the Creative Commons Attribution 4.0 International License (http://creativecommons.org/licenses/by/4.0/), which permits unrestricted use, distribution, and reproduction in any medium, provided you give appropriate credit to the original author(s) and the source, provide a link to the Creative Commons license, and indicate if changes were made. The Creative Commons Public Domain Dedication waiver (http://creativecommons.org/publicdomain/zero/1.0/) applies to the data made available in this article, unless otherwise stated.

hypertension [2], and few have effectively treated and controlled their hypertension. Research on socioeconomic disparities in prevalence, awareness, treatment, and control of hypertension is warranted to inform the development of new strategies for reducing such health inequities.

Although previous cross-sectional studies [3-5] have evaluated the health inequities in hypertension burden, they failed to disentangle the effects of adult life course and cohort processes. This is because socioeconomic determinants might vary across age and historical period over the past 30 years of large-scale societal transitions. Thus, the longitudinal data should be used to accurately 
measure such social disparities in hypertension across time. And to our knowledge, no previous longitudinal study has evaluated the socioeconomic disparities in prevalence, awareness, treatment, and control of hypertension over adult lifespan. Therefore, we research this using data from the China Health and Nutrition Survey (CHNS), which is a large-scale longitudinal survey.

\section{Related literature}

Many cross-sectional studies on socioeconomic disparities in hypertension have been conducted in both developed [6,7] and developing counties [6, 8-13]. Some studies have also analyzed the possible causes of such socioeconomic disparities [14-17].

A prospective urban-rural epidemiology study [6] conducted data from 153,996 adults from 628 communities in three high-income countries (HIC), ten upper-middleincome and low-middle-income countries (UMIC and LMIC), and four low-income countries (LIC). Results indicated the prevalence of hypertension was higher in men compared to women in HIC, LMIC, and LIC. The rates of hypertension awareness, treatment, and control were higher in urban than that in rural areas of LICs and LMICs, and they were negatively associated with educational achievement in LICs. Kearney PM and colleagues [7] found the variation in rural -urban difference in the level of prevalence, awareness, treatment and control of hypertension across countries. The prevalence of hypertension was higher in urban communities compared to rural ones in India and Thailand. However, hypertension prevalence of rural areas is equal to that of urban areas in Poland, and is even more than that of urban areas in Spain.

From the developing country setting, Luis RoseroBixby and WH Dow [11] determined socioeconomic status (SES) gradients in the different dimensions of hypertension and obesity. Results showed obesity and hypertension were worse among high-SES individuals, and lack of exercise and smoking were more common among low SES. Fernald LC and Adler NE [12] conducted a house-to-house crosssectional survey in low-income regions of rural Mexico, they found household income was positively associated with systolic blood pressure (SBP), but educational achievement was negatively associated with SBP.

In China, the National Nutrition and Health Survey Working Group [8] investigated 141,892 Chinese adults in the 2002. Results indicated the prevalence of hypertension was lower among women than men, but the rates of awareness and treatment were higher among women compared with men. The rates of prevalence, awareness, treatment, and control of hypertension were higher in urban than in rural dwellers. The 2007-2008 China National Diabetes and Metabolic Disorders Study [9] also showed the prevalence of hypertension was higher in urban than in rural areas, and was higher in men than in women. L. Cai and colleagues [13] examined how obesity was distributed across socio-economic gradients in rural China, they found the educational achievement was negatively associated with obesity, and household income was positively associated with central obesity.

Fan Yang [16] conducted an effect evaluation of community intervention trial of chronic disease in China rural areas, and indicated the intervention was more effective in these rural residents with high education than their counterparts. Galdas PM et al. [14] reviewed the key literatures about men's health-related help seeking behaviour. Results showed many studies highlighted a trend of delay in seeking help among men who become ill, "traditional masculine behaviour" was an explanation for delayed help seeking when they experience illness. Bell $\mathrm{CN}$ et al. [15] calculated the association between race/ ethnicity and hypertension by levels of social support, and found the race/ethnicity difference of hypertension among those with social support was smaller compared to those without social support; the ethnic difference was only observed among those with social support; Mexican Americans with social support were less likely to suffer from hypertension than their white counterparts. Sebastian Taylor and Alireza Marandi [17] indicated inequities in health services access, use, and benefit are determined by social, political, economic, and cultural factors in China, Cambodia and Iran.

\section{Methods}

The CHNS is a prospective household-based study designed to collect information on key public health risk factors, health outcomes, and demographic, social and economic factors across nine rounds of surveys between 1989 and 2011. Its survey protocols and process for obtaining informed consent were approved by the institutional review committees of the University of North Carolina at Chapel Hill, the National Institute of Nutrition and Food Safety, Chinese Center for Disease Control and Prevention, and the China-Japan Friendship Hospital, Ministry of Health.

The CHNS adopted a multistage, random cluster process [18] to draw the samples samples (Additional file 1: Figure S1). In the first stage, the sampling process was stratified according to geography, economic development, public resources, and health indicators and nine provinces (Heilongjiang, Liaoning, Guangxi, Guizhou, Hubei, Hunan, Henan, Jiangsu, and Shandong provinces) were selected. In the second stage, two cities and four counties were chosen for each province based on income level reported by the National Bureau of Statistics. Except one city was usually the provincial capital, the rest of them were randomly selected [18]. In the third stage, two urban 
neighbourhoods and two suburban villages were randomly selected within each city; in each selected county, one neighborhood committee was randomly selected from the town where the county government is located, as well as three townships (stratified by income: one high, one low, and two middle-income counties). One village was randomly selected in each township using the simple random sampling method. The CHNS defined these villages, townships, urban and suburban neighborhoods as 'communities', also known as primary sampling units (PSUs). In the final stage, 20 households were selected randomly from each PSU using the household roster and all members in each household were interviewed [18].

The household roster was used to follow-up each of the originally sampled households as well as new households formed from previous households. The follow-up rate was high. The CHNS attempted to follow up with households moving within PSUs or some larger urban entities, rather than the ones from one community to another. Additional details of sampling, response rates, and data quality are reported elsewhere [18-20].

Since only preschoolers and young adults aged 20-45 years were surveyed in 1989, we examined data from CHNS of the 1991, 1993, 1997, 2000, 2004, 2006, 2009, and 2011. Participants were eligible for analysis if they were 18 years or older and their blood pressure was collected, which resulted in an analytic sample of 20,174 individuals (75,729 observations) at multiple exams (mean number of exams: 4).
Data was collected by well-trained health workers at the participants' houses or a local clinic. Seated systolic/ diastolic blood pressure was measured three times by mercury sphygmomanometers on the right arm in triplicate after a 10-min rest according to a standard protocol [21]. The average value of the three measurements was used in our data analysis. Hypertension was defined as an average systolic blood pressure (SBP) of $140 \mathrm{~mm} \mathrm{Hg}$ or higher and/or an average diastolic blood pressure (DBP) of $90 \mathrm{~mm} \mathrm{Hg}$ or higher and/or self-reported current use of prescription antihypertensive medications [22]. Awareness of hypertension was defined as selfreported diagnosis of hypertension by a healthcare professional. Treatment of hypertension was defined as self-reported current use of a prescription medication for hypertension management. Control of hypertension was defined as pharmacological treatment of hypertension associated with an average SBP $\leq 140 \mathrm{~mm} \mathrm{Hg}$ and an average DBP $\leq 90 \mathrm{~mm} \mathrm{Hg}$. Current drinking was defined as alcohol intake more than once per week during the past 12 months.

The mixed-effects models (models 1, 2,3) were used to explicitly evaluate the socioeconomic disparities in hypertension because mixed effects models are particularly useful in settings where repeated measurements are made on the same statistical units (longitudinal study) [23]. These models can analysis the relationship between independent variables and a response variable, with coefficients that

Table 1 Descriptive characteristics of adult population (age $>=18$ ) who participated in the 1991-2011 China Health and Nutrition Survey ${ }^{a}$

\begin{tabular}{|c|c|c|c|c|c|c|c|c|}
\hline & Survey Year & & & & & & & \\
\hline & 1991 & 1993 & 1997 & 2000 & 2004 & 2006 & 2009 & 2011 \\
\hline Participated & 8667 & 7133 & 5290 & 6442 & 6935 & 7182 & 6716 & 7500 \\
\hline New participated & & 1096 & 3368 & 3071 & 2335 & 2008 & 2852 & 5134 \\
\hline With drowal/Died & & 1534 & 2939 & 2216 & 2578 & 2088 & 2474 & 2068 \\
\hline Age & $40.1(16.4)$ & $40.6(16.5)$ & $41.8(16.7)$ & $42.5(16.6)$ & $44.3(17.0)$ & $43.5(16.8)$ & $44.5(16.9)$ & $46.0(16.6)$ \\
\hline Gender & 48.6 & 48.8 & 49.0 & 48.9 & 48.9 & 47.3 & 46.7 & 47.0 \\
\hline Ethnicy & 94.3 & 94.3 & 94.7 & 94.9 & 94.9 & 94.8 & 94.9 & 96.1 \\
\hline Marital status & 75.5 & 74.8 & 74.6 & 75.1 & 82.1 & 83.5 & 83.3 & 84.1 \\
\hline Education year & $15.6(9.7)$ & $16.2(9.5)$ & $17.0(9.3)$ & $18.1(9.1)$ & 18.8(8.8) & 18.8(9.4) & $19.1(9.0)$ & $20.6(8.9)$ \\
\hline Medical insurance & 31.3 & 25.7 & 25.5 & 21.7 & 26.8 & 49.3 & 90.7 & 94.8 \\
\hline Household income $^{c}$ & $3036(2264)$ & $3457(2970)$ & $4257(3561)$ & $5556(5686)$ & $7149(7605)$ & $8112(11821)$ & 11579(15164) & 13887(16374) \\
\hline Community urbanicity ${ }^{d}$ & $46.1(16.2)$ & $47.6(16.4)$ & $52.3(18.0)$ & $58.2(18.1)$ & $61.4(20.2)$ & $62.6(20.0)$ & 65.5(19.0) & 69.5(19.4) \\
\hline Current drinking & 22.4 & 24.2 & 25.1 & 25.2 & 23.2 & 23.0 & 20.9 & 21.2 \\
\hline Prevalence & 14.4 & 15.8 & 20.0 & 21.0 & 24.0 & 23.3 & 29.4 & 27.9 \\
\hline Awareness & 27.4 & 27.6 & 21.3 & 32.6 & 36.4 & 42.5 & 42.8 & 55.3 \\
\hline Treatment & 16.0 & 16.4 & 14.4 & 22.9 & 27.7 & 33.1 & 35.1 & 47.6 \\
\hline Control & 3.0 & 3.1 & 2.8 & 5.3 & 8.0 & 8.8 & 9.2 & 17.6 \\
\hline
\end{tabular}

${ }^{a}$ Values presented as numbers for arbitrary values and as mean \pm SD or $\%$ for other variables

${ }^{\mathrm{c}}$ Net annual. Inflated to 2011

${ }^{\mathrm{d}}$ Measured at the community level on a 12-component continuous scale ranging from 0-120 with higher values corresponding to higher levels of urbanicity 
can change with respect to the grouping variables. We focused on gender, race/ethnicity, marital status, medical insurance, urbanization index, education years and per capita net annual household income over the life course as key socioeconomic indicators. Gender was a dummy variable coded 100 for males and zero for females. Race/ethnicity (100 for ethnic Han, and zero for other minorities), marital status (100 for Married and zero for others), and medical insurance (100 for insured and zero for uninsured) is also represented by the dummy variable. Per capita net annual household income was calculated at the household level for each survey year and inflated to 2011. Urbanization index was calculated at the community level for each survey year by a multicomponent continuous scale [24, 25]. Communities could receive a maximum of ten points for each of 12 components including population density, economic activity, traditional markets, modern markets, transportation infrastructure, sanitation, communications, housing, education, diversity, health infrastructure and social services [24, 25]. We added these key socioeconomic indicators with age and age-squared into the models to identify socioeconomic disparities in prevalence, awareness, treatment, and control of hypertension over the adult life course. The model can be formulated as follows:

$$
\begin{aligned}
Y_{i t} & =\left(\beta_{0}+\mu_{0 i}\right)+\left(\beta_{1}+\mu_{1 i}\right) \text { Age }_{i t} \\
& +\left(\beta_{2}+\mu_{2 i}\right) \text { Age }_{i t}^{2}+\left(\beta_{3}+\mu_{3 i}\right) \text { Gender }_{i t} \\
& +\left(\beta_{4}+\mu_{4 i}\right) \text { Survey Year }_{i t}+e_{i t} \\
Y_{i t} & =\left(\beta_{0}+\mu_{0 i}\right)+\left(\beta_{1}+\mu_{1 i}\right) \text { Age }_{i t}+\left(\beta_{2}+\mu_{2 i}\right) \text { Age }_{i t}^{2} \\
& +\left(\beta_{3}+\mu_{3 i}\right) \text { Gender }_{i t}+\left(\beta_{4}+\mu_{4 i}\right) \text { Survey Year }_{i t} \\
& +\left(\beta_{5}+\mu_{5 i}\right) \text { Gender }_{t i} * \text { Age }_{i t} \\
& +\left(\beta_{6}+\mu_{6 i}\right) \text { Survey Year }_{i t} * \text { Age }_{i t}+e_{i t}
\end{aligned}
$$

\begin{tabular}{|c|c|c|c|}
\hline & Model 1 & Model 2 & Model 3 \\
\hline Age & $0.19(0.08,0.29)$ & $0.26(0.15,0.38)$ & $0.27(0.13,0.42)$ \\
\hline $\mathrm{Age}^{2}$ & $0.008(0.007,0.009)$ & $0.007(0.006,0.008)$ & $0.006(0.005,0.008)$ \\
\hline Gender & $0.05(0.04,0.05)$ & $0.08(0.06,0.10)$ & $0.07(0.04,0.09)$ \\
\hline 1993 & $0.78(-0.22,1.78)$ & $2.06(-0.81,4.94)$ & $0.78(-2.39,3.95)$ \\
\hline 1997 & $3.62(2.60,4.63)$ & $-0.80(-3.79,2.19)$ & $-1.42(-4.79,1.94)$ \\
\hline 2000 & $2.98(1.98,3.98)$ & $-2.16(-5.19,0.88)$ & $-3.36(-6.94,0.21)$ \\
\hline 2004 & $3.15(2.12,4.17)$ & $-2.25(-5.50,0.99)$ & $-3.67(-7.20,-0.13)$ \\
\hline 2006 & $1.23(0.19,2.27)$ & $-0.63(-3.97,2.72)$ & $-2.75(-6.40,0.91)$ \\
\hline 2009 & $6.51(5.46,7.55)$ & $-1.32(-4.71,2.06)$ & $-4.47(-8.91,-0.75)$ \\
\hline 2011 & $3.98(2.97,4.98)$ & $-3.21(-6.48,0.05)$ & $-7.33(-10.96,-3.70)$ \\
\hline Gender*Age & & $-0.07(-0.12,-0.03)$ & $-0.05(-0.10,-0.004)$ \\
\hline $1993^{*}$ Age & & $-0.03(-0.09,0.04)$ & $0.01(-0.06,0.08)$ \\
\hline $1997^{*}$ Age & & $0.11(0.04,0.17)$ & $0.12(0.05,0.19)$ \\
\hline $2000 *$ Age & & $0.12(0.05,0.19)$ & $0.14(0.06,0.22)$ \\
\hline $2004^{*}$ Age & & $0.12(0.06,0.19)$ & $0.16(0.08,0.23)$ \\
\hline $2006^{*}$ Age & & $0.05(-0.02,0.12)$ & $0.09(0.01,0.16)$ \\
\hline $2009 * A g e$ & & $0.17(0.10,0.24)$ & $0.20(0.12,0.28)$ \\
\hline $2011 * A g e$ & & $0.16(0.09,0.22)$ & $0.20(0.13,0.28)$ \\
\hline Community urbanicity & & & $0.07(0.05,0.10)$ \\
\hline Ethnicy & & & $0.05(0.03,0.07)$ \\
\hline Marital status & & & $-0.02(-0.03,-0.01)$ \\
\hline Education years & & & $-0.07(-0.12,-0.016)$ \\
\hline Medical Insurance & & & $0.02(0.01,0.03)$ \\
\hline Household income & & & $1.68 \mathrm{E}^{-4}\left(6.21 \mathrm{E}^{-5}, 2.75 \mathrm{E}^{-4}\right)$ \\
\hline Urbanicity*household income & & & $-1.89 \mathrm{E}^{-6}\left(-3.26 \mathrm{E}^{-6},-5.17 \mathrm{E}^{-7}\right)$ \\
\hline Current Drinking & & & $0.010(0.002,0.018)$ \\
\hline
\end{tabular}

Table 2 Coefficients (95\% confidence intervals) from mixed effects models (model 1,2 and 3) predicting of the probability of Hypertension Prevalence over the Life Course among China adults 


$$
\begin{aligned}
Y_{i t} & =\left(\beta_{0}+\mu_{0 i}\right)+\left(\beta_{1}+\mu_{1 i}\right) \text { Age }_{i t}+\left(\beta_{2}+\mu_{2 i}\right) \text { Age }_{i t}{ }^{2} \\
& +\left(\beta_{3}+\mu_{3 i}\right) \text { Gender }_{i t}+\left(\beta_{4}+\mu_{4 i}\right) \text { Survey Year }_{i t} \\
& +\left(\beta_{5}+\mu_{5 i}\right) \text { Gender }_{t i} * \text { Age }_{i t} \\
& +\left(\beta_{6}+\mu_{6 i}\right){\text { Survey } \text { Year }_{i t} * \text { Age }_{i t}} \\
& +\left(\beta_{7}+\mu_{7 i}\right) \text { Ethnicy }_{i t}+\left(\beta_{8}+\mu_{8 i}\right) \text { Marital status }_{i t} \\
& +\left(\beta_{9}+\mu_{9 i}\right) \text { Education years }_{i t} \\
& +\left(\beta_{10}+\mu_{10 i}\right) \text { Urbanicity }_{i t} \\
& +\left(\beta_{11}+\mu_{11 i}\right) \text { Household Income }_{i t} \\
& +\left(\beta_{12}+\mu_{12 i}\right) \text { Urbanicity }_{i t} * \text { Household Income }_{i t} \\
& +\left(\beta_{13}+\mu_{13 i}\right) \text { Medical insurence }_{i t} \\
& +\left(\beta_{14}+\mu_{14 i}\right) \text { Current drinking }_{i t}+e_{i t}
\end{aligned}
$$

where $Y_{i t}$ is the response vectoxr for individual i at time $\mathrm{t}$ (the measurement instance for hypertension); $\mu_{0 i}, \mu_{1 i}$ $\cdots, \mu_{k i}$ are the differences between $\beta_{0}, \beta_{1} \cdots, \beta_{\mathrm{k}}$ and the intercept or slopes of subject $\underline{i}$ (random effects); $\beta_{0}, \beta_{1}$ $\cdots, \beta_{\mathrm{k}}$ are the subjects mean intercept or slopes for the above explanatory variables (fixed effects); $e_{i t}$ is the random error within subjects throughout the adult life course.

The coefficients in the Equation (1), Equation (2) and Equation (3) can be interpreted as age effect, period effect, and the influence of socioeconomic disparities in prevalence, awareness, treatment, and control of hypertension over the life course, respectively. Trajectories of the probability of hypertension prevalence across the adult life course for 1582 participants with measurements for all eight surveys among men and women was estimated by unadjusted mixed effects models stratified by baseline age group (cohort). All statistical tests were 2-sided and were performed using Stata version 12.

\section{Results}

The sample characteristics were shown in Table 1 . Curvilinear age effects were observed in prevalence, awareness, treatment, and control of hypertension (All $P<0.0001$ ) over the adult life course (Table 2, Model 1 and see Additional file 2: Table S1). Results of the complete-case analysis confirmed that prevalence of hypertension increased non-linearly with age at any given cohort (Fig. 1). Unadjusted linear mixed effects model stratified by age and gender shows that prevalence of hypertension was higher in younger birth cohorts than in older ones, particularly for men. For example, the prevalence of hypertension among males was higher in the 1934-1943 cohort than that in the 1924-1933 cohort when they were 60-80 years old, but lower than that in 1944-1953 cohort when 50-70 years old.

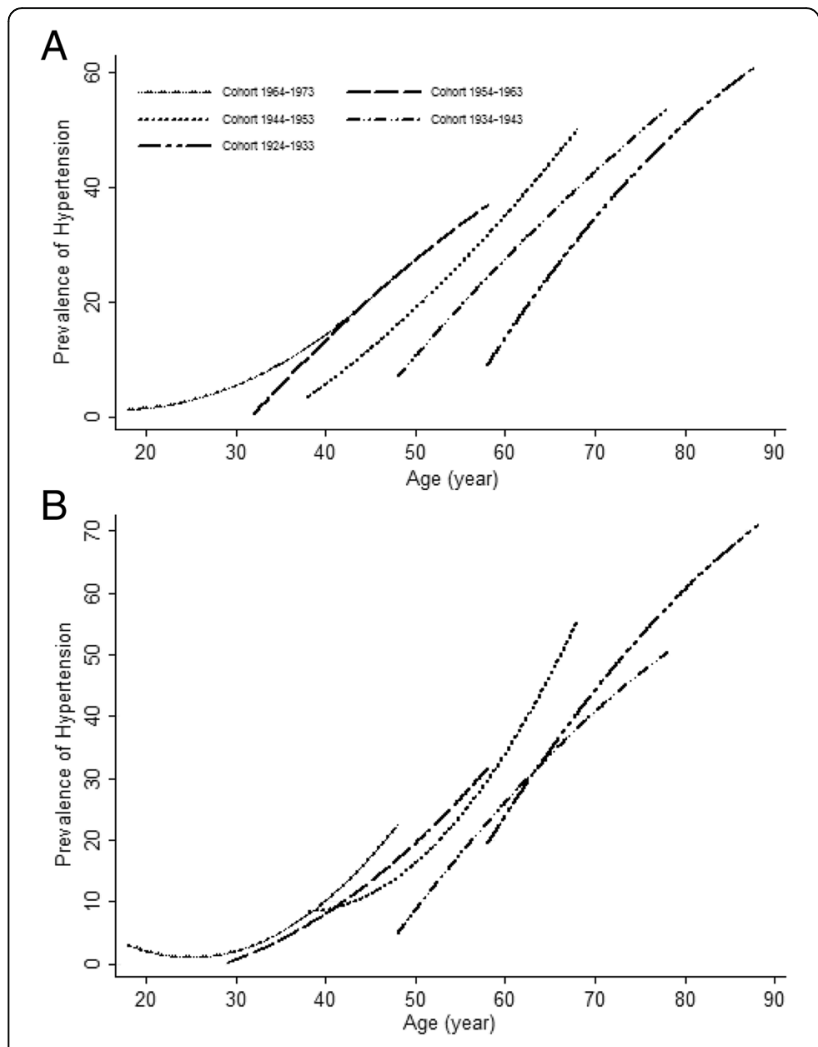

Fig. 1 Trajectories of the probability of hypertension prevalence (\%) across the life course for 1582 participants with measurements for all 8 surveys among men (A) and women (B) adult, estimated by multilevel mixed effects models stratified by baseline age group (cohort)

Hypertension was more prevalent among the males, insured and ethnic Han than their counterparts across adulthood [coefficient (95\% confidence intervals): $0.07(0.04,0.09), 0.02(0.01,0.03)$ and $0.05(0.03,0.07)$, respectively; all $P<0.0001$ ] (Table 2 , Model 3). Hypertension prevalence increased with community urbanicity and household income $(P<0.0001$ and $P=0.002$, respectively), but decreased with education years [coefficient (95\% confidence intervals): $-0.07(-0.12,-0.016)$; $p=0.009$ ] throughout the adult life course (Table 2, Model 3). Awareness, treatment, and control of hypertension were higher in ethnic Han than in ethnic minorities $(P=0.001, P=0.001$ and $P=0.027$, respectively) (Table 3). Awareness, treatment, and control of hypertension increased with urbanization (all $P<0.0001$ ). Awareness, treatment, and control of hypertension increased decreased with household income $(P=0.043$, $P=0.013$ and $P<0.0001$, respectively), but increased with education years [coefficient ( $95 \%$ confidence intervals): $0.28(0.17,0.39), 0.27(0.17,0.37)$ and $0.14(0.08,0.21)$, respectively; all $P<0.0001)$ ] over adulthood. 
Table 3 Coefficients (95\% confidence intervals) from mixed effects models (model 3) predicting of the probability of Awareness, Treatment, and Control of Hypertension over the Life Course among China adults

\begin{tabular}{|c|c|c|c|}
\hline & Awareness & Treatment & Control \\
\hline Age & $1.93(1.51,2.36)$ & $1.71(1.31,2.11)$ & $0.62(0.35,0.88)$ \\
\hline $\mathrm{Age}^{2}$ & $-0.016(-0.019,-0.012)$ & $-0.013(-0.016,-0.009)$ & $-0.006(-0.008,-0.003)$ \\
\hline Gender & $-0.05(-0.12,0.03)$ & $0.002(-0.07,0.07)$ & $-0.04(-0.08,0.01)$ \\
\hline 1993 & $-13.73(-26.83,-0.62)$ & $-4.54(-16.96,7.88)$ & $0.52(-8.27,9.31)$ \\
\hline 1997 & $-19.74(-32.63,-6.86)$ & $-4.39(-16.61,7.82)$ & $-3.64(-12.18,4.89)$ \\
\hline 2000 & $-23.66(-36.90,-10.41)$ & $-14.99(-27.53,-2.45)$ & $-8.21(-16.99,0.57)$ \\
\hline 2004 & $-31.02(-43.81,-18.23)$ & $-21.22(-33.34,-9.09)$ & $-8.45(-16.86,-0.03)$ \\
\hline 2006 & $-31.10(-44.24,-17.96)$ & $-21.56(-33.99,-9.12)$ & $-7.68(-16.30,0.93)$ \\
\hline 2009 & $-31.08(-43.89,-18.27)$ & $-25.83(-37.95,-13.71)$ & $-7.70(-16.02,0.63)$ \\
\hline 2011 & $-24.71(-37.53,-11.89)$ & $-20.53(-32.69,-8.37)$ & $-13.75(-22.06,-5.45)$ \\
\hline Gender*Age & $-0.03(-0.16,0.09)$ & $-0.10(-0.21,0.02)$ & $0.02(-0.05,0.10)$ \\
\hline 1993*Age & $0.28(0.05,0.51)$ & $0.10(-0.12,0.32)$ & $-0.02(-0.17,0.13)$ \\
\hline $1997^{*} \mathrm{Age}$ & $0.24(0.01,0.46)$ & $0.03(-0.19,0.24)$ & $0.04(-0.11,0.19)$ \\
\hline $2000^{*}$ Age & $0.44(0.21,0.67)$ & $0.30(0.08,0.52)$ & $0.15(-0.01,0.30)$ \\
\hline $2004^{*}$ Age & $0.60(0.38,0.82)$ & $0.44(0.24,0.65)$ & $0.16(0.02,0.31)$ \\
\hline $2006^{*}$ Age & $0.68(0.45,0.90)$ & $0.52(0.31,0.73)$ & $0.16(0.01,0.31)$ \\
\hline $2009^{*}$ Age & $0.71(0.49,0.93)$ & $0.64(0.43,0.84)$ & $0.16(0.01,0.30)$ \\
\hline $2011 * A g e$ & $0.74(0.52,0.96)$ & $0.68(0.47,0.88)$ & $0.36(0.22,0.50)$ \\
\hline Community urbanicity & $0.34(0.29,0.40)$ & $0.36(0.31,0.41)$ & $0.12(0.08,0.15)$ \\
\hline Ethnicy & $0.08(0.03,0.13)$ & $0.07(0.03,0.12)$ & $0.03(0.004,0.06)$ \\
\hline Marital status & $-0.01(-0.04,0.01)$ & $-0.02(-0.04,0.004)$ & $-0.003(-0.02,0.01)$ \\
\hline Education years & $0.28(0.17,0.39)$ & $0.27(0.17,0.37)$ & $0.14(0.08,0.21)$ \\
\hline Medical Insurance & $-0.004(-0.02,0.02)$ & $0.001(-0.02,0.02)$ & $-0.002(-0.01,0.01)$ \\
\hline Household income & $-2.5 \mathrm{E}^{-4}\left(-4.9 \mathrm{E}^{-4},-8.24 \mathrm{E}^{-6}\right)$ & $-2.9 E^{-4}\left(-5.1 E^{-4},-6.1 E^{-5}\right)$ & $-4.3 \mathrm{E}^{-4}\left(-5.9 \mathrm{E}^{-4},-2.8 \mathrm{E}^{-4}\right.$ \\
\hline Urbanicity*household income & $5.14 \mathrm{E}^{-6}\left(2.07 \mathrm{E}^{-6}, 8.22 \mathrm{E}^{-6}\right)$ & $6.12 \mathrm{E}^{-6}\left(3.21 \mathrm{E}^{-6}, 9.04 \mathrm{E}^{-6}\right)$ & $7.72\left(5.71 \mathrm{E}^{-6}, 9.72 \mathrm{E}^{-6}\right) \mathrm{E}^{-6}$ \\
\hline Current Drinking & $-0.033(-0.052,-0.014)$ & $-0.051(-0.069,-0.033)$ & $-0.015(-0.027,-0.003)$ \\
\hline
\end{tabular}

\section{Discussion}

In this study, we evaluated the socioeconomic disparities in prevalence, awareness, treatment, and control of hypertension over the adult life course with CHNS data. To our knowledge, few studies $[8,9]$ have definitively disentangled the effect of life course. The present study provides the first longitudinal analyses to document socioeconomic disparities in the burden of hypertension across the adult life course. The findings revealed agerelated increases in prevalence, awareness, treatment, and control of hypertension over the adult life course. Younger generations were more likely to suffer from hypertension than the older birth cohorts. Furthermore, women, ethnic minority, and population with high educational level or low household income had a lower probability of suffering from hypertension. Awareness, treatment, and control of hypertension increased with educational level, but decreased with household income throughout the adult life course. Prevalence, awareness, treatment, and control of hypertension increased with community urbanicity over the adult life course.

Our longitudinal analyses found prevalence of hypertension was higher in younger than the older birth cohorts. This may be due to lack of physical activity among younger generations, which leads to higher probability of being obese [23, 26, 27]. Hypertension prevalence was greater for men than women over adulthood, but females were not more likely to be aware of, treat and control their hypertension than males over the adult life time in our study, which is not consistent with other studies $[6,8,9,14]$. The reason of the different results may be that our longitudinal analysis controlled for age, period and socioeconomic determinants. It implied that socioeconomic factors possibly result in the low rate of hypertension awareness, treat and control among women.

Many studies showed race/ethnic differences in hypertension [8]. We found China ethnic minorities had lower prevalence of hypertension than ethnic Han, which may 
be attributable to the distributional difference of risk factors between ethnic Han and minorities, e.g. obesity [28]. However, because China ethnic minorities live in the less affluent areas with limited health care resources, they were less likely to have their hypertension diagnosed, treated and controlled. Other studies also indicated that lack of social support may cause the race/ethnicity differences of hypertension [15]. Although medical insurance can improve access to health care, we did not find significant differences between the insured and uninsured in the awareness, treatment and control of hypertension.

Community urbanicity brought the raise in awareness, treatment, and control of hypertension, but also led to an increase in prevalence of hypertension, which are consistent with other China cross sectional surveys [8]. The 2002 China National Nutrition and Health Survey also showed the urban-rural disparity in hypertension. However, hypertension burden of rural areas was equal to or even more than that of urban areas in the developed countries [10]. The reason for the mixed results may be that obesity and less physical activity are more in the urban population compared with rural population in China [29]. On the other hand, urbanization can increase the health resources to bring the raise in awareness, treatment, and control of hypertension in urban areas. Conversely, most hypertensive patients have not been diagnosed and there was a great proportion of lost to follow-up for diagnosed hypertension in rural areas.

Our study showed prevalence of hypertension decreased with education years, and hypertension with more education years also had higher rates of hypertension awareness, treatment and control, which was consistent with evidences from other developing countries [6, 12]. People with high education level tend to have fewer risk factors, and were more likely to change their unhealthy behaviors due to better access to health knowledge [16]. However, our research showed hypertension was more prevalent in high-income population. In other developing areas, low income was also found to be associated with lower SBP in the older Costa Rican [11] and in rural Mexico [12]. A Chinese study has also showed obesity increased with yearly household income [13]. Awareness, treatment and control of hypertension decreased with household income in our study, although some studies showed the income could increase the accessibility and utilization of health care services [17]. Our result contradicts several western studies because of the different stages of social development between developing and the developed countries. In China, rich people are more likely to choose unhealthy lifestyle, and thus more likely to be obese.

There are some limitations in our study. Firstly, the main limitation includes the loss-to-follow-up data. Secondly, some risk factors were unavailable, including family history of hypertension and smoking.

\section{Conclusion}

We observed age-related increases in prevalence, awareness, treatment, and control of hypertension over the adult life course; and prevalence of hypertension was at higher levels in the younger birth cohorts than in the older generations. Community urbanicity brought the raise in awareness, treatment, and control of hypertension, but also led to an increase in prevalence of hypertension. People with fewer educational years or higher income may be the disadvantaged population of hypertension in China. Hypertension prevention should address these socioeconomic determinants to reduce such health inequities.

\section{Additional files}

Additional file 1: Figure S1. The CHNS multi-stage cluster random sampling scheme. (DOCX $175 \mathrm{~kb}$ )

Additional file 2: Table S1. Coefficients (95\% confidence intervals) from mixed effects models (model 1 and 2) predicting of the probability of Awareness, Treatment, and Control of Hypertension over the Life Course among China adults. (DOC $56 \mathrm{~kb}$ )

\section{Abbreviations}

CHNS: China Health and Nutrition Survey; DBP: Diastolic blood pressure; SBP: Systolic blood pressure

\section{Acknowledgements}

This research uses data from China Health and Nutrition Survey (CHNS). We thank the National Institute for Nutrition and Health, China Center for Disease Control and Prevention, Carolina Population Center (P2C HD050924, T32 HD007168), the University of North Carolina at Chapel Hill, the NIH (R01-HD30880, DK056350, R24 HD050924, and R01-HD38700) and the NIH Fogarty International Center (D43 TW009077, D43 TW007709) for financial support for the CHNS data collection and analysis files from 1989 to 2015 and future surveys, and the China-Japan Friendship Hospital, Ministry of Health for support for CHNS 2009, Chinese National Human Genome Center at Shanghai since 2009, and Beijing Municipal Center for Disease Prevention and Control since 2011.

\section{Funding}

This work is supported by 'Study on the Vertical Integration Strategies in Health Services for Rural Patients with Chronic Diseases Based on Comprehensive Incentive Model' form the National Natural Science Fund of China (grant NO.71473130), The Measurement of Health Inequalities of Hypertension and Construction of the Mechanism Model of Its Impact Factors - Base on the Diderichsen Theory' from the general project of social science research for Jiangsu university, education department of Jiangsu province (grant NO.2017SJB161). However, the funding agencies had no role in the design, conduct analysis, and interpretation of this article.

\section{Availability of data and materials}

The datasets generated and/or analysed during the current study are available in the this repository [http://www.cpc.unc.edu/projects/china/data].

\section{Authors' contributions}

YF wrote the analysis plan and had the primary responsibility of writing this paper. DQ supervised its conduct and data analysis, reviewed and revised all drafts of this manuscript. All other authors reviewed and commented on drafts. All authors read and approved the final manuscript.

Competing interests

The authors declare that they have no competing interests. 


\section{Consent for publication}

Not applicable.

\section{Ethics approval and consent to participate}

Survey protocols, instruments and the process for obtaining informed consent for this study were approved by the institutional review committees of the University of North Carolina at Chapel Hill, the National Institute of Nutrition and Food Safety, Chinese Center for Disease Control and Prevention, and the China-Japan Friendship Hospital, Ministry of Health.

\section{Publisher's Note}

Springer Nature remains neutral with regard to jurisdictional claims in published maps and institutional affiliations.

\section{Received: 12 December 2016 Accepted: 6 June 2017}

Published online: 13 June 2017

\section{References}

1. Feng $X L$, Pang M, Beard J. Health system strengthening and hypertension awareness, treatment and control: data from the China Health and Retirement Longitudinal Study. Bull World Health Organ. 2014;92:29-41.

2. Commission on Social Determinants of Health. Closing the gap in a generation: health equity through action on the social determinants of health. Geneva: World Health Organization; 2008.

3. Lei $X$, Yin N, Zhao $Y$. Socioeconomic status and chronic diseases: The case of hypertension in China. China Econ Rev. 2012;23:105-21.

4. S Tu. socioeconomic inequalities in prevalence and control of hypertension of the rural elderly in Shandong province, China. Jinan: Shandong University: 2009.

5. Basu S, Millett C. Social Epidemiology of Hypertension in Middle-Income Countries: Determinants of Prevalence, Diagnosis, Treatment, and Control in the WHO SAGE Study. Hypertension. 2013;62:18-26.

6. Chow CK, Teo KK, Rangarajan S, Islam S, Gupta R, Avezum A, Bahonar A, Chifamba J, Dagenais G, Diaz R, Kazmi K, Lanas F, Wei L, Lopez-Jaramillo P, Fanghong $L$, Ismail NH, Puoane T, Rosengren A, Szuba A, Temizhan A, Wielgosz A, Yusuf R, Yusufali A, McKee M, Liu L, Mony P, Yusuf S, for the PURE (Prospective Urban Rural Epidemiology) Study investigators. Prevalence, Awareness, Treatment, and Control of Hypertension in Rural and Urban Communities in High-, Middle-, and Low-Income Countries. JAMA. 2013:310(9):959-68.

7. Kearney PM, Whelton M, Reynolds K, Whelton PK, He J. Worldwide prevalence of hypertension: a systematic review. J Hypertens. 2004;22:11-9.

8. Wu Y, Huxley R, Li L, Anna V, Xie G, Yao C, Woodward M, Li X, Chalmers J, Gao R, Kong L, Yang X. Prevalence, Awareness, Treatment, and Control of Hypertension in China: Data from the China National Nutrition and Health Survey 2002. Circulation. 2008;118:2679-86.

9. Gao Y, Chen G, Tian H, Lin L, Lu J, Weng J, Jia W, Ji L, Xiao J, Zhou Z, Ran X Ren Y, Chen T, Yang W. Prevalence of Hypertension in China: A Cross-Sectional Study. PLoS ONE. 2013;8(6):e65938. doi:10.1371/journal.pone.0065938.

10. Whelton PK, He J, Muntner P. Prevalence, awareness, treatment and control of hypertension in North America, North Africa and Asia. J Hum Hypertens. 2004; 18:545-51.

11. Roserobixby L, Dow WH. Surprising SES gradients in mortality, health, and biomarkers in a Latin American population of adults. J Gerontol B Psychol Sci Soc Sci. 2009;64B:105e17.

12. Fernals LC, Adler NE. Blood pressure and socioeconomic status in lowincome women in Mexico: a reverse gradient? J Epidemiol Community Health. 2008;62:e8

13. Cai L, He J, Song Y, Zhao K, Cui W. Association of obesity with socioeconomic factors and obesity-related chronic diseases in rural southwest China. Public Health. 2013;127:247-51.

14. Galdas PM, Cheater F, Marshall P. Men and health help-seeking behaviour. J Adv Nurs. 2005;49(6):616-23.

15. Bell CN, Thorpe Jr RJ, LaVeist TA. Race/Ethnicity and Hypertension: The Role of Social Support. Am J Hypertens. 2010;23(5):534-40.

16. Yang F. Effect Evaluation of Community Intervention Trial of Chronic Disease in Central and Western Rural Areas of Shandong Province. Jinan: Shandong University; 2013.

17. Taylor S, Marandi A. Social determinants of health and the design of health programmes for the poor. BMJ. 2008;337:266-9.
18. Ma Y. The Impact of socioeconomic Status and Dietary-related factors on Blood pressure among Adults in 9 Provinces of China (1991-2009). Beijing: China Center for Disease Control and Prevention; 2013.

19. China Health and Nutrition Survey. China Health and Nutrition Survey. 2013. Retrieved from. http://www.cpc.unc.edu/projects/china.

20. Popkin BM, Du S, Zhai F, Zhang B. Cohort Profile: The China Health and Nutrition Survey-monitoring and understanding socio-economic and health change in China, 1989-2011. Int J Epidemiol. 2010;39(6):1435-40.

21. Tuan NT, Adair LS, Stevens J, Popkin BM. Prediction of hypertension by different anthropometric indices in adults: the change in estimate approach. Public Health Nutr. 2010;13(5):639-46.

22. Chobanian AV, Bakris GL, Black HR, Cushman WC, Green LA, Izzo Jr JL, Jones DW, Materson BJ, Oparil S, Wright Jr JT, Roccella EJ. The Seventh Report of the Joint National Committee on Prevention, Detection, Evaluation, and Treatment of High Blood Pressure: the JNC 7 report. JAMA. 2003;289:2560-72.

23. Lindsay MJ, Penny GL, Elizabeth JM, Linda SA, Barry P. Age, Period and Cohort Effects on Adult Body Mass Index and Overweight from 1991 to 2009 in China: the China Health and Nutrition Survey. Int J Epidemiol. 2013; 42:828-37. doi:10.1093/ije/dyt052.

24. Jones-Smith JC, Popkin BM. Understanding community context and adult health changes in China: development of an urbanicity scale. Soc Sci Med. 2010;71:1436-46.

25. Jaacks LM, Gordon-Larsen P, Mayer-Davis EJ, Adair LS, Popkin B. Age, Period and Cohort Effects on Adult Body Mass Index and Overweight from 1991 to 2009 in China: the China Health and Nutrition Survey. Int J Epidemiol. 2013:42:828-37.

26. Mohsen M. Ibrahim, Albertino Damasceno. Hypertension in developing countries. Lancet. 2012:380:611-9.

27. Meng XJ, Dong GH, Wang D, Liu MM, Lin Q, Tian S, et al. Prevalence, awareness, treatment, control, and risk factors associated with hypertension in urban adults from 33 communities of China: the CHPSNE study. J Hypertens. 2011;29:1303-10.

28. Yan WL, Zheng YJ, Wu J, Chen SF, Ti XK, Li L, Liu XR. Ethnic differences in body mass index and prevalence of obesity in school children of Urumqi City, Xinjiang, China. Biomed Environ Sci. 2006;19(6):469e73.

29. Liming L, Wenzhi W, Yangfeng W, Chonghua Y, Bo W, Wenzhi W, et al., editors. The fourth report of China national health and nutrition examination survey: hypertension 2002. Beijing: People's Health; 2008. in Chinese.

\section{Submit your next manuscript to BioMed Central and we will help you at every step:}

- We accept pre-submission inquiries

- Our selector tool helps you to find the most relevant journal

- We provide round the clock customer support

- Convenient online submission

- Thorough peer review

- Inclusion in PubMed and all major indexing services

- Maximum visibility for your research

Submit your manuscript at www.biomedcentral.com/submit
) Biomed Central 